\title{
Biomechanical assessment of children requiring tibialis anterior surgical tendon transfer for residual congenital talipes equinovarus
}

\author{
Kelly Gray ${ }^{1,2^{*}}$, Paul Gibbons ${ }^{1,2}$, David Little ${ }^{1,2}$, Joshua Burns ${ }^{1,2}$ \\ From 3rd Congress of the International Foot and Ankle Biomechanics Community \\ Sydney, Australia. 11-13 April 2012
}

\section{Introduction}

Congenital talipes equinovarus (CTEV) is a deformity in which the foot is in structural equinus, varus, adductus and cavus and occurs in approximately 1 per 1000 births [1]. Despite good initial correction with the Ponseti technique, a tibialis anterior tendon transfer (TATT) is required in $20-25 \%$ of cases to correct residual dynamic supination observed during gait. Currently, no reliable or valid biomechanical measures exist to assess the need for, or effectiveness of, surgery.

\section{Materials and method}

Between August 2009 to April 2011, 20 children (average age 53 months \pm 10 months) with CTEV were assessed prior to a TATT. Assessment included range of movement (Dimeglio Scale), foot alignment in standing (Foot Posture Index), strength (hand held dynamometry), gait (pedobarography) and function (Clubfoot Disease Specific Index). These results were compared to 12 children (average age 48 months \pm 12 months) with CTEV who did not require a TATT (controls).

\section{Results}

Range of movement and function was significantly less in the TATT group $(\mathrm{p}=0.001, \mathrm{p}=0.006)$. The TATT group displayed significantly greater supination on the Foot Posture Index $(p=0.032)$ and significantly less eversion strength compared to the non-surgical group $(\mathrm{p}<0.001)$. During gait, feet of the TATT group had less contact area with ground $(\mathrm{p}=0.044)$, but increased contact time, particularly in the hindfoot $(\mathrm{p}=0.001)$, lateral midfoot $(\mathrm{p}=0.004)$

\footnotetext{
* Correspondence: KellyE@chw.edu.au

'Department of Orthopaedic Surgery, The Children's Hospital at Westmead, Sydney, NSW, 2145, Australia

Full list of author information is available at the end of the article
}

and lateral forefoot $(\mathrm{p}=0.034)$. Pressure-time integral was significantly higher in TATT group for medial and lateral hindfoot ( $\mathrm{p}=0.027 ; \mathrm{p}=0.010)$ and lateral midfoot $(\mathrm{p}=0.034)$.

\section{Conclusions}

Children with CTEV who require a TATT display objective measureable differences compared to a nonsurgical CTEV group. These measures may be useful in identifying which children require a TATT in the future.

\section{Author details}

'Department of Orthopaedic Surgery, The Children's Hospital at Westmead, Sydney, NSW, 2145, Australia. ${ }^{2}$ The University of Sydney, NSW, Australia.

Published: 10 April 2012

\section{Reference}

1. Dobbs MB, Gurnett CA: Update on clubfoot: etiology and treatment. Clin Orthop Relat Res 2009, 467:1146-1153.

\section{doi:10.1186/1757-1146-5-S1-O31}

Cite this article as: Gray et al:: Biomechanical assessment of children requiring tibialis anterior surgical tendon transfer for residual congenital talipes equinovarus. Journal of Foot and Ankle Research 2012 5(Suppl 1): O31.

Submit your next manuscript to BioMed Central and take full advantage of:

- Convenient online submission

- Thorough peer review

- No space constraints or color figure charges

- Immediate publication on acceptance

- Inclusion in PubMed, CAS, Scopus and Google Scholar

- Research which is freely available for redistribution

\section{Biomed Central}

